\title{
Unusual Antonyms: Inter-Part-Of-Speech Interaction in English Fictional Discourse
}

Natalya B. Boeva-Omelechko, 'Marina R. Zheltukhina, ${ }^{\dagger}{ }^{\top}$ Olga P. Ryabko,' Galina G. Matveeva, Elena V. Murugova ${ }^{\top}$ and Irina A. Zyubina ${ }^{i}$

\section{Abstract}

The article focuses on the phenomenon of inter-part-of-speech antonymy and types of inter-partof-speech antonymic oppositions typical of the English language and represented in authentic sources, in particular, fiction books of English-speaking writers. The paper analyses cognitive foundation and linguistic sources of the oppositions in question describe their range within each part of speech as well as contextual means of intensifying the oppositional contrast. The authors argue that the traditional point of view, according to which only words belonging to the same part of speech can form antonymic oppositions, is insufficient and claims that inter-part-of-speech antonymy has a semantical and grammatical nature as it is based on the ability of the language to give different categorial form to the same fragments of reality. The results of the research show that practically all works of fiction include inter-part-of-speech antonymic oppositions, which thus can be treated as a regular language phenomenon. The paper contributes to the theory of parts of speech, giving additional information about their interaction and its cognitive basis. It also enriches the theory of antonymy, proposing a wide approach to antonymic oppositions.

Kevwords: Inter-part-of-speech interaction, Antonymy, The Paradigm of Nomination, Lexical Meaning, Grammatical Meaning, Asymmetry of Meaning.

\footnotetext{
${ }^{\dagger}$ Department of English Language Theory and Practice, Southern Federal University, 344082, 33 Bolshaya Sadovaya Str., Rostov-on-Don, Russian Federation

I Department of Theory of English Language, Volgograd State Socio-Pedagogical University, 400066, 27 Lenin Ave, Volgograd, Russian Federation

${ }^{*}$ Corresponding Author, Email: zzmr@mail.ru

'Department of English Language for Humanities Faculties, Southern Federal University, 344082, 33 Bolshaya Sadovaya Str., Rostov-on-Don, Russian Federation

' Department of World Languages and Cultures, Don State Technical University, 344000, 1 Gagarin Square, Rostov-onDon, Russian Federation

${ }^{i}$ Department of Linguistics and Professional Communication, Southern Federal University, 344082, 33 Bolshaya Sadovaya Str., Rostov-on-Don, Russian Federation

(C) 2018 Boeva-Omelechko et al. This is an Open Access article distributed under the terms of the Creative Commons Attribution License (http://creativecommons.org/licenses/by/2.0), which permits unrestricted use, distribution, and reproduction in any medium, provided the original work is properly cited.
} 


\section{Introduction}

One of the main types of interaction between units of the language is antonymic relations, which stipulates the necessity of investigation of inter-part-of-speech antonymy represented by antonymic oppositions with members, belonging to different parts of speech. According to the traditional point of view, only words belonging to the same part of speech can form antonymic oppositions (Cruse, 1986; Ljung, 1974; Lyons, 1977).

Inter-part-of-speech antonyms have opposite lexical meanings, like systemic antonyms, but different grammatical forms and syntactic functions. It can be explained by the cases of asymmetry of meaning and categorial form of parts of speech when a word has a lexical meaning typical of one part of speech and a grammatical form typical of some other part. The objective character of inter-part-of-speech antonymy is confirmed by the existence of oxymoron, employing the juxtaposition of two normally contradictory words belonging to different parts of speech (Finnegan, 1989).

According to, I.E. Rodicheva (1976), oxymorons are not always necessary for the formation of the antonymic opposition. A number of linguists (Miller, 1990; Murugova, 2018; Repina, et al., 2018; Ryabko, 2016a,b; Zyubina et al., 2017) say that in the fictional discourse words belonging to different parts of speech can also form antonymic oppositions thus overcoming the boundaries of the language system.

We adopt the definition of discourse as a semiotic process realized different discursive practices (Ilyin, 2001). We also rely on theoretical principles formulated by Van Dijk (2004), especially his approach to discourse as a process having verbal and non-verbal constituents, i.e. societal, political or cultural context.

Fictional discourse can be defined as an act of producing fiction (Panizza, 2017). The parallel term literary discourse is also used in linguistics (Van Dijk, 2004) and "some works of fiction are literary works, and some are not" (Searle, 1979:
319). However, as the difference between them is rather fuzzy and "nowadays most works of literature are fictional" (ibid.), in this paper we shall use the term fictional discourse in the interpretation mentioned above.

Works, devoted to antonymy and antonyms (Kastovsky, 1982; Lehrer and Lehrer, 1982; Ogden, 1932), becomes the main theoretical references in our study. According to the narrow approach, antonymy presupposes gradation, and so only qualitative adjectives can be treated as real antonyms (Lyons, 1995). According to the broad approach, all parts of speech can form antonymic oppositions (Harford and Heasely, 2007). We adopt the latter approach widely spread in linguistics.

According to definitions of parts of speech, they are:

- "classes of words differentiated by their meaning and syntactic functions in the sentence" (Fennigan, 1989: 1083);

- "belong to a class in that they have the same grammatical properties and structural possibilities as other members of the class" (Quirk et al., 1982: 25);

The ability of the language to give different categorial content to the same fragments of reality, stipulating the existence of inter-partof-speech antonymic oppositions, can be explained with the lexical paradigm of nomination. According to M. Blokh (2000), "the unity of notional lexemes finds its essential demonstration in an inter-class system of derivation that can be presented as a formal four-stage series permeated the lexicon ... The general order of classes in the series evidently corresponds to the logic of mental perception of reality, by which a person discriminates, first, objects and their actions, the properties of the former and the latter", as strength - to strengthen - strong - strongly.

The article focuses on inter-part-of-speech antonymic oppositions. The paper aims to give a more detailed analysis of the cognitive foundation of inter-part-of-speech antonymy and to reveal antonymic oppositions typical of each part of speech in the English language 
based on their representation in the fictional discourse.

\section{Material and Methods}

About 2000 examples extracted from authentic sources (fiction books of English-speaking writers), with the following interpretation of these examples. Examples were analysed with the help of the following methods.

The method of oppositions (Trubetskoy, 1960): Members of such opposition must have in the structures of their meanings a number of common features, that is, the basis of comparison, and a pair of antonymous features, which ensure contrast of meanings. In case of antonymy we deal either with privative oppositions, "when one member is seen as marked by the presence of a feature, which its opposite member lacks", or with equipollent oppositions "the members of which are seen as logically equivalent to each other, contrasted neither gradually nor by a binary feature" (Crystal, 2008: 342).

This method was complemented with seme (componental) analysis. Semes, treated in linguistics as minimal (irreducible) components of meaning operating within a specific semantic field (Crystal, 2008). Speaking about semantic structure of word, we deal with hierarchy of semes (Arnold, 1991).

It is necessary to define a categorial lexical seme or classeme - "relatively abstract semantic features shared by lexical items belonging to different semantic fields". Among semes it is possible to distinguish a hyperseme or a topical seme which serves as a name of the semantic field (in our case it is the seme sound). In the process of analysis, we single our grammatical categorial (part-of-speech) semes, lexical categorial semes (classemes), hyperseme, and more particular lexical semes.

The method of contextual analysis, revealing the contextual means of intensifying the oppositional contrast and helping to prove that oppositions in question are really antonymic ones, was very important for us. In this paper, we adopt the definition of a context as a specific part of an utterance (or text) near or adjacent to a unit which is the focus of attention (Crystal, 2008).

\section{Results and Discussion}

The ability of the language to present the same fragment of reality in different categorial form leads to formation of inter-part-of speech antonymic oppositions. Indeed if we deal with two opposite qualities this contrast, existing in objective reality, won't disappear if these qualities will be presented in different categorial form. In other words, we argue that antonyms, as any other words, belong to certain paradigms of nomination, which can be called antonymous paradigms of nomination (Boeva, 2001). They can include words with the same root (1) and with different roots (2):

(1) Belief - to believe - believing believingly; disbelief - to disbelieve unbelieving - unbelievingly

(2) Despair - to despair - despairing despairingly; hope - to hope - hopeful hopefully

Each member of one paradigm has an antonym belonging to the same part of speech in the other one (despair - hope, to despair - to hope, despairing - hopeful, despairingly - hopefully). We deal with horizontal relations, i.e. antonyms belonging to the same part of speech. Radial relations between members belonging to different parts of speech are also possible. For instance, the noun despair can form antonymic oppositions with the verb hope, adjective hopeful and adverb hopefully, but not only with the noun hope.

The existence of such antonymous paradigms of nomination is one of the most important sources of inter-part-of-speech antonyms. In the examples below the opposition nounadjective (smallness - large) (3) conveys the contrast of small and big sizes, and the opposition verb - adjective (die - immortal) (4) conveys the contrast of mortality and immortality:

(3) Alternatively, perhaps, Dill later thought, the smallness of the gun made the fist look large (Thomas, 1987). 
(4) Only the more complicated organisms die. Simple cells are immortal (Byatt, 1994).

We conclude that besides positive antonymous paradigms of nomination there also exist negative ones:

(5) Fancy - to fancy - fanciful - fancifully; not fancy (no fancy) - not to fancy - not fanciful - not fancifully

Each element of a negative paradigm has a mark of negation and is opposed to a corresponding member of the positive paradigm (fancy - no fancy, to fancy- not to fancy, fanciful- not fanciful, fancifully - not fancifully). In this case, we deal with horizontal relations, but radial is also possible (fanciful no fancy, fanciful - not to fancy, fanciful - not fancifully).

The existence of negative antonymous paradigms of nomination also stipulates the formation of inter-part-of-speech antonymic oppositions. In example (6) the opposition is formed by a noun (speculator) and a verb with a mark of negation (does not speculate). It conveys the contrast of an action and inaction, intensified by adversative conjunction but.

(6) You are the speculator. That may be your way of wisdom. However, Lilly does not even speculate (Lawrence, 1977).

The suppletive completions in paradigms of nomination are also a source of inter-part-ofspeech antonymic oppositions. For instance, the English language does not have a noun derived from the adjective old, which must be the first element in the corresponding paradigm of nomination. It leads to phrasemic completion old age capable of forming interpart-of-speech antonymic oppositions with the elements of the paradigm youth - be young young (7). The opposition adjective (old) - noun (youth) conveys the contrast of ages.

(7) Somehow in old age, he preserved youth... (Ustinov, 1993).

The absence of adverbs in incomplete English paradigms of nomination is often compensated by prepositional word-groups, which form inter-part-of-speech antonymic oppositions with adverbs in the antonymous paradigm:

(8) I'm sure if I called Den Kendall, he'd find a senior coed to take you to classes and back (Segal, 1995).

The important source of completion of the lexical paradigm of nomination is the paradigm of non-finite forms of the verb, which always accompanies the basic paradigm of nomination. In example (8), an infinitive (to sell) and a noun with a mark of negation (no sale) form the opposition, conveying the contrast of action and inaction.

(9) You are going to sell him, sir? - You're damn right, I am. But it's a gift, so no sale here in Johannesburg (Smith, 1992).

In oppositions between finite and non-finite forms of the verb and non-finite forms belonging to different classes we deal with incomplete inter-part-of-speech antonymy, because each class of non-finite forms with its own lexical-grammatical peculiarities, which distinguish it from finite forms and other classes of non-finite ones, belongs to the whole system of the verb. In example (10) we see the opposition of the finite form of the verb (tied) and the infinitive (to untie), conveying the contrast of directions of actions; in example (11) - the opposition of the infinitive (to exclude) and participle 1 (including), conveying the contrast of exclusion and inclusion.

(10) Then he tied her to a tree in the backyard. Many people heard her, but nobody tried to untie her (Atwood, 1984).

(11) At times, their closeness seemed to exclude everyone else, including their children (Kellerman, 1997).

Contextual inter-part-of-speech antonymic oppositions consist of words, which do not belong to antonymous paradigms of nomination but have in the structures of their meanings semes typical of members of certain antonymous paradigms. These semes did not belong to the nucleus of their meanings and 
actualised only in micro-contexts. Example (12) presents the oppositions of the noun snow having the seme 'cold' in the structure of its meaning, and the adjective hot and the verb burn, having the seme 'warmth'. The oppositions snow - hot and snow - burn are formed by analogy with the oppositions of systematic antonyms, belonging to antonymous paradigms of nomination.

(12) She also developed a fierce hatred for the snow... - She longed for the hot cracked earth which burned her bare feet (Ustinov, 1993).

\section{Opposition a Noun - an Adjective}

A noun can form oppositions with different parts of speech. Most often nouns used for the indirect nomination of qualities, i.e. having a categorial lexical seme of quality, form oppositions with adjectives, having the same or different roots with them. The members of these oppositions usually belong to antonymous paradigms of nomination as in example (13).

(13) He was healthy and healthy people are embarrassed by sickness; she could remember that (Atwood, 1984).

The adjective healthy and the noun sickness represent in different grammatical forms the contrast of physical states due to antonymous semes 'health'/'sickness' in structures of their meanings. The contrast is intensified by the use of antonyms in interrelated syntactical functions of the subject and the object connected with the same predicate.

The noun, forming the opposition with the adjective, can be a part of a word-group, filling in a missing element in a paradigm of nomination:

(14) In itself my gesture was unimportant, but I suspected it had assumed vast importance to them since their world was so constricted (Ustinov, 1993).

The noun importance in the word-group to assume importance, which completes the verb in the corresponding paradigm of nomination, forms an antonymic opposition with the adjective unimportant due to antonymous semes 'presence'/'absence of a feature'. The contrast is intensified with the help of the adversative conjunction but.

Negative paradigms of nomination - a noun can be used independently or in a word-group, which fills in a missing element in a paradigm of nomination or is synonymous to an element of a paradigm expressed by one lexeme:

(15) Harkin asked for a no-strike guarantee in the future, but Easter would not commit....- no one in the courtroom knew for certain why the jury was on strike (Grisham, 1996).

The adjective no-strike, derived from the negative syntactical construction, forms an antonymic opposition with the noun strike in the word-group to be on strike, synonymous to the verb to strike in the corresponding paradigm of nomination, conveying the contrast of action or inaction.

Contextual oppositions a noun - an adjective. The contrast of their meanings is based on the actualization of peripheral antonymous semes in structures of these meanings, revealed with the help of definitions in dictionaries and the general sense of the context (16), (17).

(16) The weather had changed, or perhaps we had finally been dragged free of the drizzle that was constant in Hue. Now it was sunny and warm... (Theroux, 1975).

The noun the drizzle and the adjective sunny can be treated as contextual inter-part-ofspeech antonyms due to the actualization of antonymous semes 'wetness'/'dryness'. The contrast is intensified with the help of the adverb now, which shows the change of the situation.

(17) ... the night was filled with the odour of rain on dry earth (Smith, 1992).

The noun rain and the adjective dry can be treated as contextual inter-part-of-speech antonyms. 


\section{Opposition a Noun - a Verb}

A noun and a verb are the two opposite ways of categorisation of experience (Kozlova, 1997). However, they can form inter-part-of-speech antonymic oppositions, realising the contrast of semantics on the level of the semantic structure of the sentence.

Nouns and verbs, forming antonymic oppositions, as well as antonymous nouns and adjectives, belong to antonymous paradigms of nomination:

(18) I mean it's the traditional grand finale to a career, and I've barely started (Segal, 1995).

The use in one micro context of the noun finale and the verb start, having antonymous semes 'end'/'beginning', emphasises the contrast of these meanings, intensifying by the conjunction and showing the difference of two situations.

The verb can form an antonymic opposition with a noun belonging to a word-group, which fills in a missing element in a paradigm of nomination or is synonymous to it:

(19) I had drifted into sleep again, and when I woke with a start the bed was empty (Durrel, 1991).

The noun sleep in the word-group drift into sleep and the verb wake are antonymous due to antonymous semes 'sleep'/'wake'. The contrast is intensified by a combination of conjunctions and when showing the difference between the two situations.

The members of the oppositions in question can belong to negative paradigms of nomination:

(20) The Queen had never seen him look like that and she panicked. He felt no panic or pain, although in fact he had suffered a concussion... (Conran, 1982).

The antonymous semes 'excitement'/'calmness', conveying the contrast of emotional states, stipulates the formation of the antonymic opposition panicked - no panic.
This contrast is intensified by reversed syntactical parallelism.

Antonymic oppositions with non-finite forms of the verb:

(21) ... the texture of her skin had altered, losing the moisture of youth, drying out so that it creased around her eyes... (Smith, 1992).

The members of the opposition moisturedrying (noun - participle 1) have antonymous semes 'wetness'/'dryness' in structures of their meanings. Described oppositions can include nouns derived from syntactical constructions:

(22) Communism is strictly for the havenots, and everyone wants to have (Ustinov, 1993).

Contextual oppositions a noun - a finite/nonfinite form of the verb:

(23) Then he put aside his gravity and broke out laughing... (Carre, 1984).

The noun gravity forms the opposition, and the gerund is laughing having antonymous semes 'gloom'/'gaiety'. The conjunction intensifies the contrast and showing the change of the situation.

\section{Opposition a Noun - an Adverb}

Such oppositions contain nouns, belonging to prepositional word-groups, performing the function of adverbial modifiers. These wordgroups fill in missing adverbs in paradigms of nomination. The oppositions in question can be divided into several groups, i.e. oppositions reflecting the contrast of:

- directions of movement (24);

- spatial localisation, including localisation in abstract spheres (25);

- temporal localization (26);

- manner or attendant circumstances (27).

(24) Bare feet stuck into carpet slippers, she shuffled to the telephone booth at the back of the hall. Then she shuffled back again (Conran, 1982).

The opposition conveys the contrast of directions of movement due to antonymous 
semes 'forward'/back' in structures of meanings in structures of meanings of the members of the opposition. The contrast is intensified by adverb then showing the change of situations.

(25) On the surface she was inanimate, but beneath, in the buried jungle of her consciousness, there was the stirring of primitive impulses, and this stirring was agony (Glasgow, 1985)

The opposition conveys the contrast of localisation due to antonymous semes 'exteriority'/ 'interiority'. The adversative preposition intensifies the contrast but.

(26) Moreover, unless you learn to be your own doctor by the time you are thirty, you never will afterwards (Snow, 1983).

The opposition conveys the contrast of temporal localisation due to antonymous semes 'precedence'/'posteriority'. The contrast is intensified by syntactical parallelism.

(27) They sat in groups, and they sat alone (Grisham, 1996).

The opposition conveys the contrast of manner of action due to antonymous semes 'individual'/'group'. The contrast is intensified by syntactical parallelism.

\section{Opposition a Verb - an Adjective}

The formation of this type of oppositions is stipulated by the fact that both a verb and an adjective belong to one onomasiological category of quality. The difference is that a verb expresses a dynamic quality, and an adjective - a static one (Kozlova, 1997).

Antonymous verbs and adjectives belong to complete or incomplete paradigms of nomination:

(28) He dried his wet right hand by running it through his dark copper hair... (Thomas, 1987).

The adjective wet and the verb dry contain in structures of their meanings antonymous semes 'wetness'/'dryness', which form the basis of the semantic contrast.
Contextual antonymic oppositions a verb - an adjective:

(29) Out in the sunshine, he looked pale beside her. Miraculous three weeks of fine weather had tanned her face, neck and arms... (Tremain, 1994).

The verb tan and the adjective pale form the opposition, conveying the contrast of colours, due to peripheral antonymous semes 'black'/'white' in structures of their meanings.

Non-finite forms of the verb:

(30) We have tried to talk to the kid, but he has been very uncooperative. - ... it is important for the kid to cooperate (Grisham, 1993).

The structures of meanings of the members of the opposition an adjective (uncooperative)infinitive (to cooperate) contain antonymous semes 'inaction'/'action'. The contrast is intensified by syntactical parallelism.

\section{Opposition an Adverb - an Adjective}

An adverb belongs to notional parts of speech alongside with a noun, a verb and an adjective. Adverbs can form antonymic oppositions with nouns belonging to word-groups. They can also form oppositions with adjectives which, like adverbs, have a categorial grammatical seme of quality but correlate, in contrast to adverbs, with substantive referents (Blokh, 2000) (31).

(31) Man is not a rational being either; he is irrationally controlled by fear (Conran, 1982).

The opposition is formed by the adjective rational and the adverb irrationally, having antonymous semes 'presence'/'absence of a feature'. The contrast is intensified by reversed syntactical parallelism.

\section{Oppositions of Notional and Functional Words}

Functional words can also be elements of interpart-of-speech antonymic oppositions. It is possible because notional words can have a categorial lexical seme 'relation' in structures of their meanings and such functional words as prepositions possess a categorial grammatical 
seme with the same name. The following oppositions are possible.

\section{Opposition a verb - a preposition}

The verb and the preposition can belong to one conceptual sphere:

(32) Haviland doesn't care a damn about what you and I are up against or what we want (Wilson, 1950).

The preposition against forms the opposition and the verb want due to antonymous semes 'rejection'/'acceptance' in structures of their meanings. The alternative preposition or intensify the contrast. The fact that preposition and verb belong to the same conceptual sphere, which serves as the basis for comparison of opposition members, can be proved by experimental transformation. In its result, the verb want will be opposed not to preposition, but to the same verb in the negative form: "Haviland doesn't care what you and I don't want or what we want".

\section{Opposition an adverb - a preposition}

Among adverbs there exist those of space and time. They are capable of forming antonymous oppositions with prepositions, which express spatial and temporal relations in prepositional phrases. These oppositions can express the contrast of:

- spatial localisation (33);

- temporal localisation (34);

(33) Ladies and gentlemen: everything that's pictured, painted and advertised outside, you will see within the walls of this tent... (Sheldon, 1996).

The opposition is formed by the preposition within and the adverb outside due to antonymous semes 'interiority'/'exteriority' in structures of their meanings. The contrast is intensified by syntactical parallelism.

(34) She had considerable means, Maman, but I was only made aware if her inheritance after our marriage. I was a bit put out that I did not hear about it before (Robins, 1978);
The opposition is formed by the preposition after and the adverb before due to antonymous semes 'precedence'/'posteriority' in structures of their meanings. The contrast is intensified by syntactical parallelism.

\section{Opposition an adjective - a preposition}

The contrast of spatial and temporal relations can be also expressed be inter-part-of-speech antonymic oppositions formed by prepositions and adjectives:

(35) Clumsily using his left hand, Sandor started cutting the bottom wire while Felix worked on the wire above it (Conran, 1982).

The opposition is formed by the adjective bottom and the preposition above due to antonymous semes 'bottom'/'top' in structures of their meanings. The contrast is intensified by the conjunction while stressing the difference of two actions.

\section{Oppositions of Functional Words}

These oppositions are formed by prepositions and conjunctions sharing the same categorial grammatical seme 'relation'. They convey the contrast of temporal relations due to antonymous semes 'precedence'/'posteriority' in structures of their meanings. This contrast is intensified by syntactical parallelism direct (36) or reversed (37).

(36) He called me before you were married. They were married three months after that, in January, on New Year's Day (Steel, 1993).

(37) I cannot operate a horse until I check everything twice. Check every valve, check the pump, check the oxygen. After that, I can send a horse to sleep (Francis, 1991).

\section{Conclusion}

Practically all works of fiction include interpart-of speech antonymic oppositions, which can be treated as a regular language phenomenon. Inter-part-of-speech antonymy has a semantic and grammatical nature as it is based on the ability of the language to give 
different categorial form to the same fragments of reality. This ability can be explained by the notion of the lexical paradigm of nomination.

Between members of paradigms, two types of relationships are possible: horizontal, uniting antonyms belonging to one part of speech, and radial, uniting words belonging to different parts of speech. Antonymous paradigms can also be negative if each element of the paradigm has a mark of negation and is opposed to a corresponding element of a positive paradigm.

The analysis of sources of inter-part-of-speech antonymic oppositions allows to reveal interpart-of-speech antonymic oppositions typical of different parts of speech in the English language and describe their peculiarities.

The results of the study give the opportunity to prove the objective and regular character of inter-part-of-speech antonymy. They contribute to the theory of parts of speech, giving additional information about their interaction and its cognitive basis. They also enrich the theory of antonymy, proposing a wide approach to antonymic oppositions.

\section{References}

Arnold, I.V. (1991). Principles of Scientific Research in Linguistics. Moscow: Vysshaya Shkola.

Atwood, M. (1984). Bodily Harm. Toronto: Seal Books.

Blokh, M.Y. (2000). A Course in Theoretical English Grammar. Moscow: Vysshaya Shkola.

Boeva, N. B. (2001). Grammatical Antonymy in Modern English, PhD Thesis. Moscow: Moscow State Pedagogical University.

Byatt, A.S. (1994). On the Day that E.M. Forster Died. In Contemporary British Stories, Oxford: Perspective Publication, pp. 6786.

Carre, J. Le. (1984). The Little Drummer Girl. New York: Alfred Knopf Inc.
Conran, Sh. (1982). Lace. London, UK: Penguin Books.

Cruse, D. (1986). Lexical Semantics. Cambridge: Cambridge University Press.

Crystal, D. (2008). A Dictionary of Linguistics and Phonetics. Oxford: Blackwell Publishing, LTD.

Durrel, L. (1991). Clea. London: Penguin Books.

Finnegan, E.G. (Ed.) (1989). New Webster' Dictionary of the English Language. College Edition. Delhi: Surjeet Publications.

Francis, D. (1991). Comeback. London: Pan Book.

Glasgow, E. (1985). Barren Ground. New York: Mariner Books.

Grisham, J. (1993). The Client. New York: Island Books.

Grisham, J. (1996). The Runaway Jury. New York: Island Books.

Harford, J., Heasley, B. (2007). Semantics. Cambridge: Cambridge University Press.

Ilyin, I. P. (2001). Dilogy. In A.N. Nikolykin (ed.), Literary Encyclopedia of Terms and Notions. Moscow: Intelvak, p. 232.

Kastovsky, D. (1982). 'Privative Opposition' and Lexical Semantics, Studia Anglica Posnaniensia, 14, 29-43.

Kellerman, F. (1997). Serpent's Tooth. New York: Avon Books.

Kozlova, L.A. (1997). Problems of Functional Convergence of Parts of Speech in Modern English. Barnaul: Barnaul State Pedagogical University.

Lawrence, D.H. (1977). Aaron's Rod. Harmondsworh: Penguin Books.

Lehrer, A., Lehrer, K. (1982). Antonymy, Linguistics and Philosophy, 5(4), 483-501.

Ljung, M. (1974). Some Remarks on Antonymy, Language (Journal of Linguistic Society of America). 50(1), 74-88. 
Lyons, J. (1995). Linguistic Semantics. An Introduction. Cambridge: Cambridge University Press.

Lyons, J. (1977). Semantics. Cambridge: Cambridge University Press.

Miller, E.N. (1990). The Nature of Lexical and Phraseological Antonymy. Saratov: Saratov State University.

Murugova, E. (2018). Linguacognitive Mechanisms of Conceptual Contaminants Integration in the Modern English Language, The European Proceedings of Social \& Behavioural Sciences. Available at http://www.futureacademy.org.uk/files/i mages/upload/WUT2018F59.pdf

Ogden, C. K. (1932). Opposition. London: Kegal Paul, Trench Tubner \& Co, LTD.

Panizza, Ch. (2017). Fictional Names and Fictional Discourse, PhD Thesis. Barselona: University of Barselona.

Quirk, R. Greenbaum, S., Leech, G., Svartvik, J. (1982). A University Grammar of English. Moscow: Vysshaya Shkola.

Repina, E.A., Zheltukhina, M.R., Kovaleva, N.A., Popova, T.G., Garcia Caselles, C. (2018). International Media Image of Russia: Trends and Patterns of Perception, Xlinguae Journal, 11(2), 557-565.

Robins, D. (1978). Mad is the Heart, North Yorkshire: Magna Large Print Books.

Rodicheva, E.I. (1976). Psycholinguistic Analysis of Lexical Antonymy, PhD Thesis. Moscow, Russia: Moscow State University.

Ryabko, O.P. (2016a). Parametric Motivation Bases of Floranimic Nomination, Proceedings of Southern Federal University. Philology, 3, 104-111.

Ryabko, O.P. (2016b). Space-Time Continuum of the Object in Cognitive Process of Nomination, Science Journal of Volgograd State University, 4, 190-196.
Searle, J. (1979). The Logic Status of Fictional Discourse, New Literary History, 6(2), 319332.

Segal, E. (1995). Prizes. New York: Fawcett Books.

Sheldon, S. (1996). If Tomorrow Comes. London: Harper Collins Publishers.

Smith, W. (1992). The Sound of Thunder. London, UK: Mandarin.

Snow, C.P. (1983). Strangers and Brothers. New York: Charles Scribner's Sons.

Steel, D. (1993). Vanished. New York: A Dell Book.

Theroux, P. (1975). The Great Railway Bazaar. London: Penguin Books.

Thomas, R. (1987). Briarpatch. Harmondsworth: Penguin Books.

Tremain, R. (1994). A Shooting Season. In Contemporary British Stories, Oxford, UK: Perspective Publication, pp. 159-172.

Trubetskoy, N. (1960). Principles of Phonology. Moscow: Publishing House of Foreign Literature.

Ustinov, P. (1993). God and the State Railways. London: Michael O'Mara Books, LTD.

Van Dijk, T. (2004). Discourse Knowledge and Ideology. In M. Pütz, J.A. Neff, T. A. van Dijk (eds.), Communicating Ideologies. Multidisciplinary Perspectives on Language, Discourse and Social Practice, Bern: Peter Lang, pp. 5-38.

Wilson, M. (1950). Live with Lightning. London: W.H. Allen.

Zyubina, I.A., Matveeva, G.G., Zheltukhina, M.R., Slyshkin, G.G., Shevchenko, A.V. (2017). Forensic Prosecutor's Speech as a Speech Genre, XLinguae Journal, 10(3), 312-323. 